2012s-28

\title{
Non-Renewable Resource Supply: Substitution Effect, Compensation Effect, and All That
}

\author{
Julien Daubanes, Pierre Lasserre
}

Série Scientifique
Scientific Series

\section{Montréal}

Octobre 2012

(C) 2012 Julien Daubanes, Pierre Lasserre. Tous droits réservés. All rights reserved. Reproduction partielle permise avec citation du document source, incluant la notice $($.

Short sections may be quoted without explicit permission, if full credit, including (C) notice, is given to the source.
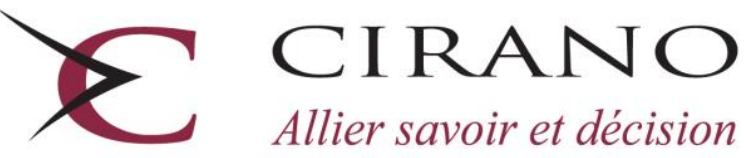

Allier savoir et décision

Centre interuniversitaire de recherche en analyse des organisations 


\section{CIRANO}

Le CIRANO est un organisme sans but lucratif constitué en vertu de la Loi des compagnies du Québec. Le financement de son infrastructure et de ses activités de recherche provient des cotisations de ses organisations-membres, d'une subvention d'infrastructure du Ministère du Développement économique et régional et de la Recherche, de même que des subventions et mandats obtenus par ses équipes de recherche.

CIRANO is a private non-profit organization incorporated under the Québec Companies Act. Its infrastructure and research activities are funded through fees paid by member organizations, an infrastructure grant from the Ministère du Développement économique et régional et de la Recherche, and grants and research mandates obtained by its research teams.

\section{Les partenaires du CIRANO}

\section{Partenaire majeur}

Ministère du Développement économique, de l'Innovation et de 1'Exportation

\section{Partenaires corporatifs}

Autorité des marchés financiers

Banque de développement du Canada

Banque du Canada

Banque Laurentienne du Canada

Banque Nationale du Canada

Banque Royale du Canada

Banque Scotia

Bell Canada

BMO Groupe financier

Caisse de dépôt et placement du Québec

Fédération des caisses Desjardins du Québec

Financière Sun Life, Québec

Gaz Métro

Hydro-Québec

Industrie Canada

Investissements PSP

Ministère des Finances du Québec

Power Corporation du Canada

Rio Tinto Alcan

State Street Global Advisors

Transat A.T.

Ville de Montréal

\section{Partenaires universitaires}

École Polytechnique de Montréal

HEC Montréal

McGill University

Université Concordia

Université de Montréal

Université de Sherbrooke

Université du Québec

Université du Québec à Montréal

Université Laval

Le CIRANO collabore avec de nombreux centres et chaires de recherche universitaires dont on peut consulter la liste sur son site web.

Les cahiers de la série scientifique (CS) visent à rendre accessibles des résultats de recherche effectuée au CIRANO afin de susciter échanges et commentaires. Ces cahiers sont écrits dans le style des publications scientifiques. Les idées et les opinions émises sont sous l'unique responsabilité des auteurs et ne représentent pas nécessairement les positions du CIRANO ou de ses partenaires.

This paper presents research carried out at CIRANO and aims at encouraging discussion and comment. The observations and viewpoints expressed are the sole responsibility of the authors. They do not necessarily represent positions of CIRANO or its partners. 


\title{
Non-Renewable Resource Supply: Substitution Effect, Compensation Effect, and All That ${ }^{*}$
}

\author{
Julien Daubanes ${ }^{\dagger}$, Pierre Lasserre ${ }^{*}$
}

Résumé / Abstract

The interaction of supply and demand is at the root of market and other equilibria. Yet no systematic synthetic treatment of non-renewable resource supply exists; equilibrium analyses or welfare statements usually are formulated without any systematic decomposition into supply and demand. In this note, we examine the supply decision of individual non-renewable resource suppliers facing given prices. We establish instantaneous restricted (fixed reserves, treated as capital) and unrestricted supply functions. We decompose the effect of a price change into an intertemporal substitution effect and a stock compensation effect. The later arises when the stock of reserves to be extracted is endogenous. We show that the substitution effect always dominates so that a price increase at some date always causes supply to decrease at all other dates. Thus, despite the formal resemblance of resource supply over the time space with demand over the spectrum of goods, there is no such thing as a possible complementarity between resources extracted at different dates. Yet, as this theory of non-renewable resource supply makes clear, this is what researchers seeking exceptions to the green paradox are trying to identify. Nor is there any peculiarity similar to the Giffen paradox or to the inferior good paradox in resource supply. Besides unifying the treatment of conventional good supply and nonrenewable resource supply, this theoretical exercise also shows how to avoid supply aggregation problems that make several existing results or modeling approaches questionable. The properties, first established within a parsimonious model, are shown to hold in a very general setup.

Mots clés/Keywords : Non-renewable resource supply, price effect, stock effect, substitution effect, supply theory, demand theory, green paradox.

Codes JEL: Q38, D21

\footnotetext{
* We thank participants at various seminars and conferences: Montreal Natural Resources and Environmental Economics Workshop; SURED Conference; annual conference of the EAERE; CESifo Workshop; Paris School of Economics - CEPREMAP - CDC Workshop; CREE annual conference; Toulouse School of Economics; Université du Québec à Montréal. Particular thanks go to Gérard Gaudet, Michael Hoel, Matti Liski, Ngo Van Long, David Martimort, Charles Mason, Rick van der Ploeg, François Salani`e, Steve Salant, and Cees Withagen. Financial support from the Social Science and Humanities Research Council of Canada, the Fonds Québécois de recherche pour les sciences et la culture, the CIREQ and the CESifo is gratefully acknowledged. ${ }^{\dagger}$ CER-ETH, Center of Economic Research at ETHZ, Swiss Federal Institute of Technology, Zurich, E-mail address: jdaubanes@ethz.ch

* Département des sciences économiques, Université du Québec à Montréal, CIRANO and CIREQ, E-mail address: lasserre.pierre@uqam.ca
} 


\section{INTRODUCTION}

In this note, we formulate a simple theory of resource supply that extends the standard microeconomic modeling of supply to non-renewable resources $;^{1}$ we assume the path of producer prices to be given and we study the effect of a price change. This new but highly orthodox framework can be used to analyze the green paradox or other policy-induced changes in extraction by the time-honored method of partial equilibrium analysis.

When total cumulative extraction is taken as given, an exogenous price change occurring at any date modifies the relative marginal profit from extracting at that date relative to other dates and thus entails a pure intertemporal substitution effect. ${ }^{2}$ A change in the resource price path faced by producers may also affect ultimately exploited reserves, both because some existing reserves may become economic or cease to be economic as a result of the price change, and because exploration and discoveries as well as reserve development are affected by the price change. We call this the stock effect and we show that the substitution effect always dominates the stock effect. Consider an increase in price at some particular date leaving prices at all other dates unchanged; the pure intertemporal substitution effect increases supply at that date and reduces supply at all other dates; the stock effect results in an increase in ultimately extracted reserves. It follows that supply increases at the date of the price rise as the stock effect and the substitution effect work in the same direction. At all other dates, since the substitution effect dominates the stock effect, it follows that supply diminishes.

These results make so much sense that they appear trivial. Yet resource supply differs from regular supply. Exhaustible resource supply presents an analogy with classical demand

\footnotetext{
${ }^{1}$ In fact we are following up on a task first undertaken by Burness (1976); understanding and explaining the extraction path has been central to the resource literature ever since. Burness specifically inquired about the effect on the extraction path of changing the exogenous price, assumed to be constant throughout the extraction period.

${ }^{2}$ This is the essential cause of the green paradox as initially formulated (Sinn, 2008).
} 
theory: resource producers allocate a stock of resource to different dates in a way that is comparable to the way consumers allocate their income to different expenditures on different goods. The time space in resource supply plays a similar role as the good space in demand, while the stock constraint in resource supply is not unlike the budget constraint in demand theory. Yet the analogy is not an isomorphism. For example the famous law of supply, which says that the supply of a good increases if its price rises ${ }^{3}$, has no demand equivalent: a Giffen good is such that its demand increases if its price rises, unlike ordinary goods. We show that there is no such paradox in resource supply: the law of supply holds for all non-renewable resources. Another paradox of demand is illustrated by inferior goods: their demand diminishes when income increases. Yet no similar phenomenon arises with non-renewable resource supply: given a price path, supply does not diminish at any date if reserves are exogenously increased.

The supply of a conventional good or service is independent from the price of another good or service as long as their production costs are independent. The supply of a nonrenewable resource at one date is affected by its price at another date even when the cost of extraction at one date is independent from the cost of extraction at all other dates. This is because the so-called augmented marginal extraction cost includes a resource scarcity rent, the opportunity cost of extracting the scarce resource, that connects extraction costs at all dates to each other: a change in the price of the resource at any date affects the rent at all dates, which in turn affects the supply at all dates. Questions about intertemporal substitution and compensation effects do not arise in standard supply theory. In the case of non-renewable resource, these questions have always been the subject of substantial research efforts; currently, for example, much research activity revolves around the green paradox, both at the policy and the theoretical levels.

\footnotetext{
"The law of supply holds for any price change. Because, in contrast with demand theory, there is no budget constraint, there is no compensation requirement of any sort..." (Mas-Colell et al., 1995, p. 138)
} 
Reserves to be used for extraction are produced by exploration and development efforts in a way similar to the generation by labor of income or wealth to be allocated to the demand for goods and services. This is an important aspect of resource supply. We assume that the stock of reserves is produced prior to extraction via exploration and development. Just as income is earned and fully used up in demand theory, reserves are developed and then completely exhausted, as in Gaudet and Lasserre (1988) and Fischer and Laxminarayan (2005). ${ }^{4}$ Exploration and development are sensitive to the rent that accrues to the extractor during the exploitation of the resource. This rent is affected by future supply prices and in turn determines the stock effect mentioned earlier. Furthermore, the constitution of reserves is necessarily subject to decreasing returns to scale as exploration prospects are finite. If such was not the case, non-renewable resources would be indefinitely reproducible like conventional commodities in the long run; the resource rent would reduce to the constant quasi-rent associated with expenditures in exploration and reserve development; the intertemporal substitution effect of resource supply would not materialize.

In Section 2, a parsimonious model of non-renewable resource supply illustrates how the effect of a price change occurring over part of the extraction period can be decomposed into a substitution effect and a stock compensation effect and allows us to show that the substitution effect dominates the compensation effect. Section 2 also draws the distinction between short term and long term, and adapts the well-known concepts of restricted (McFadden, 1978) cost and supply functions to the case of resource supply.

It is customary to use the apparatus of supply and demand to study policies. This is the realm of partial equilibrium analysis. Applying this apparatus to non-renewable resource

\footnotetext{
${ }^{4}$ Following Gordon (1967), Hoel (2010), Gerlagh (2011), van der Ploeg and Withagen (2012) and Grafton, Kompas and Long (2012) in their analysis of the green paradox, consider that some part of the resource may be left unexploited; the same is true of the Herfindahl-type model of Fischer and Salant (2012, p. 17). This can be rational if no costs are experienced to develop the resource, or if an unexpected change in the economics of extraction such as a drop in the price, makes extraction uneconomic. Indeed, while income is transformed into consumption at no cost, reserves are costly to extract; however it would not be rational to incur costs for the development of reserves not to be extracted.
} 
markets is simple but requires taking into account the intertemporal nature of resource supply. This is outlined in Section 3 under perfect competition or in presence of market power; technical details are relegated to the Appendix. As an example, we show that the green paradox holds under very general conditions.

Non-renewable resources are heterogenous. In Section 3, with details in the Appendix, we consider many heterogenous deposits with different costs of extraction and different costs of exploration and development. The timing of deposit development and exploitation is endogenous and part of the producer's supply problem. The results of Section 2 are confirmed. The multiple deposit model has the further advantage of avoiding aggregation issues arising in the well-known Ricardian model initiated by Gordon (1967).

\section{A Synthetic TheORY OF EXHAUstible RESOURCE SUPPLY}

A quantity $x_{t} \geq 0$ of a non-renewable resource is supplied at each of a countable set of dates $t=0,1,2, \ldots$. The initial stock $X>0$ of the resource is finite and treated as exogenous at this stage, with $\sum_{t \geq 0} x_{t} \leq X$. The producer price is denoted by $p_{t} \geq 0$. The stream of prices $p \equiv\left(p_{t}\right)_{t \geq 0}$ is taken as given by the producers and treated as exogenous at this stage. ${ }^{5}$ Net spot extraction revenues are denoted $\pi_{t}\left(x_{t}, p_{t}\right)$, where the function $\pi_{t}$ may be time varying, is increasing in both arguments, is twice differentiable, and satisfies $\frac{\partial^{2} \pi_{t}(.)}{\partial x_{t}^{2}}<0$ and $\frac{\partial^{2} \pi_{t}(.)}{\partial x_{t} \partial p_{t}}>0 .{ }^{6}$

\footnotetext{
${ }^{5}$ We will show that the results extend to a partial equilibrium setting where prices are endogenously determined on markets.

${ }^{6}$ As it depends on the output level, $\pi_{t}$ is clearly not a profit function, which would result from the maximization of net revenues with respect to output, given output and factor prices (Varian, 1992, pp. 25, 26). However, it may be assumed that the cost of producing $x_{t}$ is minimized given factor prices, with factor prices omitted from the notation: $\pi_{t}=p_{t} x_{t}-C_{t}\left(x_{t}\right)$, where $C_{t}$ is a cost function (p. 26); this justifies assumptions $\frac{\partial^{2} \pi_{t}(.)}{\partial x_{t}^{2}}<0$ and $\frac{\partial^{2} \pi_{t}(.)}{\partial x_{t} \partial p_{t}}>0$. Some authors model extraction costs as dependent on the stock of reserves to reflect the fact that increasing scarcity justifies incurring higher costs to reach and extract the resource. This would imply here to define the cost function as a restricted or short-run cost function $C_{t}\left(x_{t}, X_{t}\right)$, treating the stock of reserves $X_{t}$ as a quasi-fixed input (p. 26). We discuss this modeling and deal more explicitly with resource heterogeneity in Section 3, by allowing deposits of different development and extraction costs to be exploited over different, endogenous, periods.
} 
It is assumed that $\pi_{t}\left(x_{t}, p_{t}\right)>0$ for some $x_{t}>0$ at least at one date, so that exploitation is warranted.

The stock of reserves to be exploited by a mine does not become available without some prior exploration and development efforts. Although exploration and exploitation often take place simultaneously at the aggregate level (e.g. Pindyck, 1978, and Quyen, 1988; see Cairns, 1990, for a comprehensive survey of related contributions), at the microeconomic level of a deposit they occur in a sequence, as in Gaudet and Lasserre (1988) and Fischer and Laxminarayan (2005). This way to model the supply of reserves is particularly adapted to the problem under study because it provides a simple and natural way to isolate the effect of an anticipated price change on the size of the exploited stock at the firm level. Specifically, assume that the cost $E(X)$ of developing an initial, exploitable stock $X$ at date 0 is twice differentiable, increasing, strictly convex, and satisfies $E(0)=0$ and $E^{\prime}(0)=0$. The property $E^{\prime}(0)=0$ that the marginal cost of reserves development is zero at the origin is introduced because it is sufficient to ensure that a positive amount of reserves is developed. It thus rules out uninteresting situations where resource prices do not warrant the production of any reserves.

For simplicity, we assume the rate of discount $r \geq 0$ to be independent of time. ${ }^{7}$ Since the development of reserves is costly, the optimum plans of the producers will always bind the exhaustibility constraint. In other words, leaving part of the developed stock ultimately unexploited does not maximize cumulative net discounted revenues. For a given price sequence $p$, the cumulative value function corresponding to a producer's optimum is

$$
\max _{\left(x_{t}\right)_{t \geq 0}, X} \sum_{t \geq 0} \pi_{t}\left(x_{t}, p_{t}\right)(1+r)^{-t}-E(X)
$$

\footnotetext{
${ }^{7}$ As spot revenues may be time-varying, the constancy of $r$ amounts to a normalization without any loss of generality.
} 
subject to

$$
\sum_{t \geq 0} x_{t}=X
$$

Denoting by $\lambda$ the Lagrange multiplier associated with constraint (2), the necessary firstorder conditions characterizing the optimum extraction path at dates where extraction is strictly positive $\operatorname{are}^{8}$

$$
\frac{\partial \pi_{t}\left(x_{t}, p_{t}\right)}{\partial x_{t}}(1+r)^{-t}=\lambda, \forall t \geq 0
$$

and, for the choice of initial reserves,

$$
E^{\prime}(X)=\lambda
$$

(3) is the Hotelling rule stating that the marginal profit from extraction must be constant over time in present value, equal to $\lambda$, the unit present-value of reserves underground, called the Hotelling scarcity rent. (4) is a standard supply relationship that sets marginal cost equal to price. The price in this case is the unit scarcity rent and is defined implicitly; in other words reserves are the output of a production process whose technology is described by the cost function $E$. However reserves are not like conventional goods that can be produced under constant returns to scale, because of the scarcity of exploration prospects. The supply of reserves is thus a strictly increasing function of the rent: ${ }^{9}$

$$
X=X(\lambda) \equiv E^{\prime-1}(\lambda)
$$

(3) implicitly defines the solution $x_{t}$ as a function which is increasing in the current price $p_{t}$ and decreasing in the rent $\lambda$ :

$$
x_{t}=x_{t}\left(p_{t}, \lambda\right), \forall t \geq 0 .
$$

\footnotetext{
${ }^{8}$ If the price is too low at some date, production may be interrupted before exhaustion, and start again once prices are high enough. The first-order condition during production interruptions (it must also hold after exhaustion) is $\frac{\partial \pi_{t}\left(0, p_{t}\right)}{\partial x_{t}}(1+r)^{-t}<\lambda$.

${ }^{9}$ The finiteness of exploration prospects amounts to a fixed factor being imposed on the production process. Hence reserves are produced under rising marginal costs.
} 
Combining all relations (6) into (2), we obtain that the rent is a function increasing in all prices $p \equiv\left(p_{t}\right)_{t \geq 0}$ and decreasing in the stock $X$ :

$$
\lambda=\lambda(p, X) .
$$

Substituting (7) into (6) gives the restricted supply functions, one at each date:

$$
x_{t}=\widetilde{x}_{t}(p, X) \equiv x_{t}\left(p_{t}, \lambda(p, X)\right), \forall t \geq 0 .
$$

Conditional on the initial reserve stock $X$ and given the sequence $p$ of prices, these functions determine how the suppliers allocate extraction from the stock to different dates. Unlike the restricted supply of a conventional good which only depends on its own price and on the quantity of some factor, the restricted resource supply function at $t$ further depends on resource prices at all other dates. This is so despite the fact that the same standard technological assumptions hold: the extraction cost at one date does not depend on the extraction cost at another date, just as the cost of producing one good is independent of the cost of producing another good.

Hotelling's lemma is obtained from the optimized value function by use of the envelope theorem for constrained problems. That is, substituting (8) and (7) into the Lagrangian function associated with Problem (1) and differentiating with respect to $p_{t}$, while holding the restricted level of $X$ and its multiplier as well as all extraction rates constant, gives the restricted supply at $t .{ }^{10}$ Variable factor prices, that is the prices of the factors entering the extraction technology, are omitted for simplicity.

The restricted supply function $\widetilde{x}_{t}$ is strictly increasing in $X$. Holding the reserve level unchanged, consider the partial effects of prices, that is the direct price effects. $\widetilde{x}_{t}(p, X)$ is strictly increasing in $p_{t}$ and strictly decreasing in any $p_{T}, T \neq t$. This can be shown as

\footnotetext{
${ }^{10}$ Hotelling's lemma is obtained similarly in the case of non-restricted supply functions defined further below. The non-restricted profit function is obtained by replacing the restricted level of $X$ and the rent $\lambda$ by their optimized values $X^{*}(p)$ and $\lambda^{*}(p)$ defined further below.
} 
follows. By (8), $\frac{\partial \widetilde{x}_{t}}{\partial p_{T}}=\frac{\partial x_{t}\left(p_{t}, \lambda(p, X)\right)}{\partial p_{T}}+\frac{\partial x_{t}}{\partial \lambda} \frac{\partial \lambda(p, X)}{\partial p_{T}}$, where the first term on the right is zero unless $T=t$, as $x_{t}\left(p_{t}, \lambda\right)$ is not directly dependent on prices other than the contemporary price. The second term is clearly negative whether $T=t$ or $T \neq t$ since $x_{t}$ decreases in $\lambda$ while $\frac{\partial \lambda(p, X)}{\partial p_{T}}$ is clearly positive since a rise in the resource price at any date cannot reduce the rent. It follows that $\frac{\partial \widetilde{x}_{t}(p, X)}{\partial p_{T}}$ is negative for $T \neq t$ while a contemporary rise in price involves two effects working in opposite directions. However, if extraction diminishes at all dates $t \neq T$, it must increase at $t=T$ for otherwise reserves would not be exhausted, which would be suboptimal. Consequently, in case of a contemporary price rise, the direct price effect given by the first term must dominate the second term that operates via the resource rent.

Consider the choice of initial reserves. While (5) is a standard stock supply relation, the price $\lambda$ is not a standard exogenous price but an endogenous variable. To find the supply of reserves as a function of exogenous prices, denote by $X^{*}$ the stock of reserves at the producers' optimum in Problem (1). The value of the unit rent at the producers' optimum is $\lambda^{*}=\lambda\left(p, X^{*}\right)$. By (5), the optimum amount of reserves satisfies $X^{*}=X\left(\lambda^{*}\right)=X\left(\lambda\left(p, X^{*}\right)\right)$, which implicitly defines $X^{*}$ and $\lambda^{*}$ as functions of $p$ :

$$
X^{*}=X^{*}(p) \text { and } \lambda^{*}=\lambda^{*}(p) \equiv \lambda\left(p, X^{*}(p)\right) \text {. }
$$

Thus the supply of reserves depends on the whole sequence of resource prices, although this can be summarized into one single rent. Here too factor prices are omitted for simplicity: they are the prices of the factors entering the extraction process because they affect the optimum rent, but also the prices of the factors entering the exploration and development process which are omitted arguments of the $E$ cost function.

Restricted supply or factor demand as well as restricted cost or profit functions are usually interpreted as representations of the short run. In the long run, the restricted factor is variable. This interpretation is adequate here, exploration and reserve development being 
analogous to capital investment. Just as capital goods are produced, reserves in (9) are the outcome of a production process. Then they are used as a factor of production in the resource production process that generates the restricted supply (8). ${ }^{11}$

The optimal (unrestricted) resource supply levels and supply functions are defined as

$$
x_{t}^{*}=x_{t}^{*}(p) \equiv \widetilde{x}_{t}\left(p, X^{*}(p)\right), \forall t \geq 0 .
$$

Like the restricted resource supply, the (unrestricted) supply of a non-renewable resource differs from a conventional supply function under identical standard technological assumptions in that it not only depends on its own price, the current price, but also on the prices at all other dates.

Let us study the effect of a change in price at date $T$ on supply at date $t$. One must distinguish between a change at the same date $T=t$ and a change at $T \neq t$. From (10), this can be decomposed into a direct price effect and a stock compensation effect:

$$
\frac{d x_{t}^{*}}{d p_{T}}=\left.\frac{\partial \widetilde{x}_{t}(.)}{\partial p_{T}}\right|_{X=X^{*}}+\frac{\partial \widetilde{x}_{t}(.)}{\partial X} \frac{\partial X^{*}(.)}{\partial p_{T}}
$$

When $T=t$, the total price effect may be called the own price effect; since $\widetilde{x}_{t}($.$) is increasing$ in both $p_{t}$ and $X$, and as resource prices always affect developed reserves positively, the own price effect is positive. Expression (11) when $T=t$ illustrates the Le Châtelier principle, which says that the long-run elasticity is higher than the short-run elasticity.

When $T \neq t$, the direct price effect in (11) may be called the pure substitution effect as it reflects the reallocation of an unchanged reserve stock to extraction at a date different from $T$; as (8) makes clear, this substitution effect only arises via the effect of the rent on the $x_{t}$ function: $\left.\frac{\partial \widetilde{x}_{t}(.)}{\partial p_{T}}\right|_{X=X^{*}}=\left.\frac{\partial x_{t}(.)}{\partial \lambda} \frac{\partial \lambda(.)}{\partial p_{T}}\right|_{X=X^{*}}$. Also by (8), the stock compensation effect can be

\footnotetext{
${ }^{11}$ Although this is not usually modeled, capital does get depleted (worn out) by production at a rate that depends on the rate of production. However conventional capital can be replenished in a plant while this is not, or only partially, true of the reserves of a mine. On the related subjects of resource substitution and sustainability, see the huge literature initiated with the 1974 Symposium of the Review of Economic Studies.
} 
itself decomposed into $\frac{\partial \widetilde{x}_{t}(.)}{\partial X} \frac{\partial X^{*}(.)}{\partial p_{T}}=\frac{\partial x_{t}(.)}{\partial \lambda} \frac{\partial \lambda(.)}{\partial X} \frac{\partial X^{*}(.)}{\partial p_{T}}$ so that the total cross-price effect can be factorized as follows:

$$
\frac{d x_{t}^{*}}{d p_{T}}=\frac{\partial x_{t}(.)}{\partial \lambda}\left(\left.\frac{\partial \lambda(.)}{\partial p_{T}}\right|_{X=X^{*}}+\frac{\partial \lambda(.)}{\partial X} \frac{\partial X^{*}(.)}{\partial p_{T}}\right), T \neq t
$$

where the term between brackets turns out to be the total derivative of $\lambda(p, X)$ with respect to $p_{T}$, decomposed into a direct price effect at constant initial reserves, and the effect on the rent of the change in initial reserves induced by the price change. It can be shown that resource prices at all dates affect the rent positively, i.e. $\frac{d \lambda^{*}}{d p_{T}} \geq 0 .{ }^{12}$ Consequently,

$$
\frac{d x_{t}^{*}}{d p_{T}}=\frac{\partial x_{t}(.)}{\partial \lambda} \frac{d \lambda^{*}}{d p_{T}} \leq 0, \forall t \neq T
$$

implying that the stock compensation effect is never high enough to offset the pure substitution effect. ${ }^{13}$

Although reminiscent of the decomposition of Marshallian demand, the decomposition of the change in resource supply at $t$ following a price change at $T \neq t$ into a pure substitution effect and a stock compensation effect is not isomorphic to the Slutsky decomposition. The substitution effect and the stock compensation effect of a resource price change are illustrated in Figure 1 for the case of two periods, which corresponds to the two-good representation of demand theory. Assuming prices $p_{0}$ and $p_{1}$, point $A=\left(x_{0}, x_{1}\right)$ in Figure 1 depicts the producer optimum. Given a stock of reserves $X$, periods 0 and 1 extraction levels are ${ }^{12}$ Formally, the definition of $X^{*}=X\left(\lambda\left(p, X^{*}\right)\right)$ yields $\frac{\partial X^{*}(.)}{\partial p_{T}}=\frac{\left.X^{\prime}(.) \frac{\partial \lambda(.)}{\partial p_{T}}\right|_{X=X^{*}} \text {, implying that the term }}{1-\frac{\partial \lambda(.)}{\partial X} X^{\prime}(.)}$,
between brackets in (12) can be factorized as $\frac{d \lambda^{*}}{d p_{T}}=\left.\frac{\partial \lambda(.)}{\partial p_{T}}\right|_{X=X^{*}}\left(\frac{1}{1-\frac{\partial \lambda(.)}{\partial X} X^{\prime}(.)}\right)$, which is positive since $\frac{\partial \lambda(.)}{\partial X}$
is negative. By (9), it also follows that $\frac{d X^{*}}{d p_{T}}$ is positive.
${ }^{13}$ We have assumed decreasing returns to the development of reserves - increasing marginal cost of devel-
opment, i.e. strict convexity of the cost function $E$. This assumption reflects the finiteness of extraction
and exploration prospects and is essential to the result.
Suppose on the contrary that the development of reserves were subject to constant returns to scale:
$E(X)=e X$. As before, $\lambda$ would give the present value of each reserve unit so that $\lambda=e$. The rent, thus
determined by the technology, would then be insensitive to variations in prices $p$, and resource supply at $t$
would only depend on current resource price by $(8)$. Constant returns to scale in the development of $X$ make
all cross-price effects on extraction vanish, just like in the classical theory of supply under separable cost. 
chosen such that producers reach the highest possible two-period iso-profit curve $\mathrm{e}^{14} \bar{\pi}$. The optimum allocation $\left(x_{0}, x_{1}\right)$ is thus at the point of tangency between the $\bar{\pi}$ iso-profit curve and the exhaustibility constraint, the -45 degree line which expresses the trade-off between quantities extracted in Period 1 and quantities extracted in Period 2 in such a way that $x_{0}+x_{1}=X$. Unlike the case of Marshallian demand, this linear constraint is not affected by changes in prices. Also, while prices do not affect iso-utility curves, they affect the slope of iso-profit curves: iso-profit curves may cross at different prices.

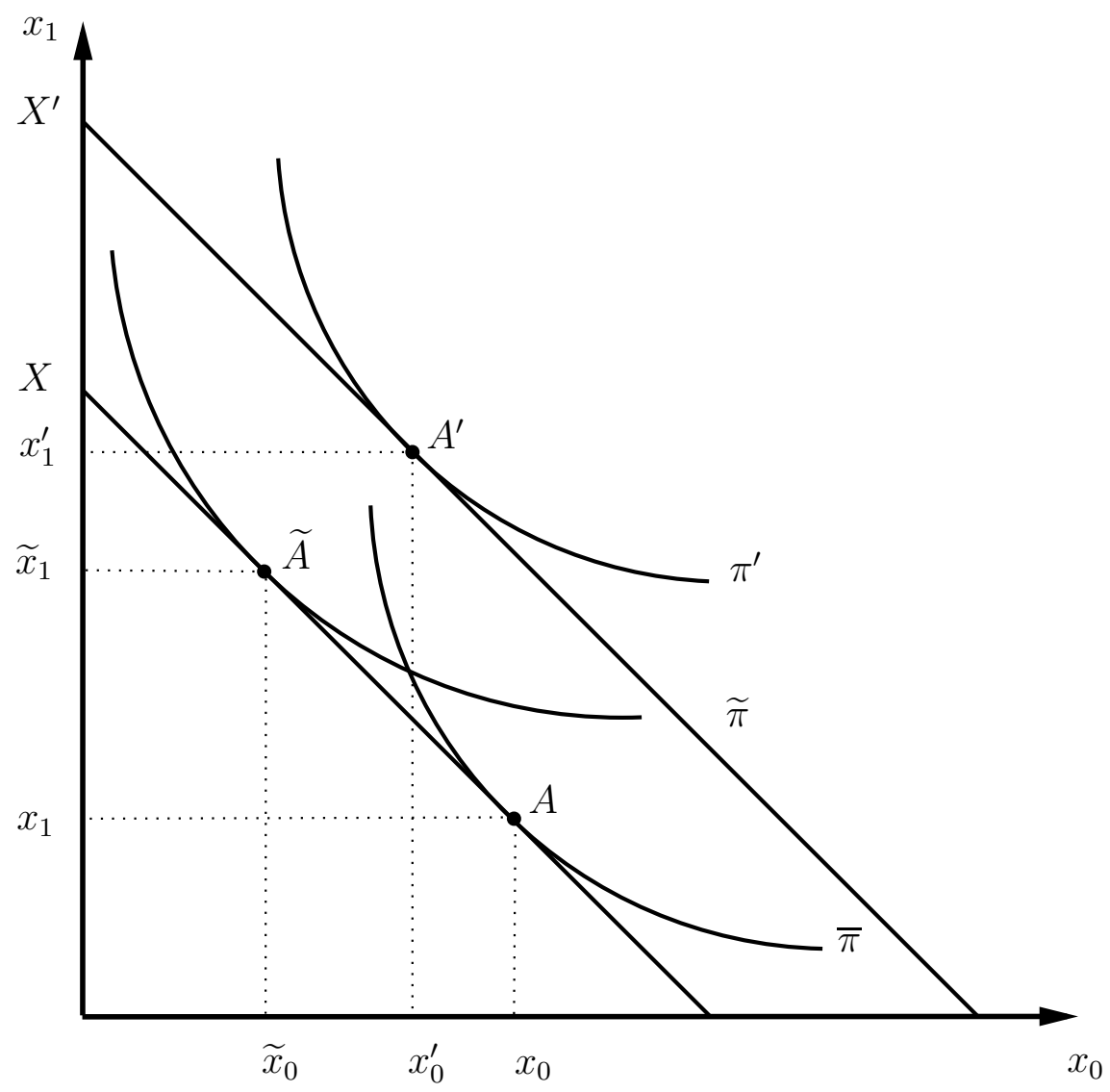

Figure 1: Price effect decomposition with $p_{1}^{\prime}>p_{1}$

\footnotetext{
${ }^{14}$ In Figure 1, the iso-profit curves correspond to the two-period profit, conditional on $X$ and before deduction of the sunk exploration cost $E(X): \bar{\pi}=\pi_{0}\left(x_{0}, p_{0}\right)+(1+r)^{-1} \pi_{1}\left(x_{1}, p_{1}\right)$. From the assumption that the $\pi_{t}$ functions are concave in extraction flows, iso-profits curves are decreasing and convex.
} 
Consider a rise in $p_{1}$ to $p_{1}^{\prime}>p_{1}$. The price change implies that all iso-profit curves become flatter at any given feasible level of $x_{0}$. If the stock of reserves remains unchanged at $X$, the new tangency point is along the same exhaustibility constraint and along the iso-profit

curve of level $\tilde{\pi}>\bar{\pi}$, at point $\widetilde{A}$ above $A$, so that $\widetilde{x}_{0}<x_{0}$ and $\widetilde{x}_{1}>x_{1}$. The move from $A$ to $\widetilde{A}$ represents the substitution effect.

However the rise in price leads producers to increase reserve development to $X^{\prime}$. Taking this stock effect into account brings the new optimum to $A^{\prime}$. It is clear that $x_{1}^{\prime}>\widetilde{x}_{1}>x_{1}$. Unlike the Slutsky decomposition, there is no possibility of a commodity analogous to a Giffen good, whose supply would diminish as a result of a rise in its price. Moreover, in the case of non-renewable resource supply, the substitution effect always dominates the compensation effect, so that, by (13), $x_{0}^{\prime}$ must be lower than $x_{0}$ following the rise in $p_{1}$. There is no such thing as resource supply complements; quantities extracted at different dates are always substitutes.

\section{Partial Equilibrium AND policy ANAlysis, market POWER, Heterogenous RESOURCES, AGGREGATION}

Policy induced changes are more complex than the above analysis of supply for two main reasons. First, policy-related price changes usually take place over an extended period rather than at a single date; second, the policy usually affects prices indirectly, because it affects the demand for the resource. For example the green paradox is often described as the effect on current or near-future resource supply of policies reducing resource demand over some extended future period via various forms of assistance to alternative energy sources. Suppose that resource demand decreases at all dates $T \in \Delta$, where $\Delta$ is a strict subset of dates, and remains unchanged otherwise. The analysis just presented allows a conventional partial equilibrium analysis to be performed by exploiting the properties of resource supply derived from Section 2. The upward sloping supply curve at $t \notin \Delta$ is negatively affected by prices 
at $T \in \Delta$. Whether demand reductions are unanticipated and not accompanied by any adjustment in the stock of reserves, or anticipated and associated with a drop in developed reserves, the analysis of the previous section carries over to each of the changes occurring at dates belonging to $\Delta$. The price parameters in (6) should simply be replaced by the inverse resource demand; reductions in demand at $T \in \Delta$ increase supply at all $t \notin \Delta$, confirming the validity of the green paradox. ${ }^{15} \mathrm{~A}$ formalization of this partial equilibrium analysis is given in the Appendix.

Although convention has it that a monopoly has no supply curve, the partial equilibrium analysis approach applies to extractive firms with market power just as it does in the static partial equilibrium analysis of monopoly. A firm that enjoys market power on the market for the extracted resource solves Problem (1) subject to (2) except that it is aware of the incidence on prices of its quantity decisions: marginal profits in (3) no longer reflect the partial effect of quantities on revenues $\frac{\partial \pi_{t}\left(x_{t}, p_{t}\right)}{\partial x_{t}}$ as under competition, but their total effect $\frac{d \pi_{t}\left(x_{t}, p_{t}\right)}{d x_{t}}=\frac{\partial \pi_{t}\left(x_{t}, p_{t}\right)}{\partial x_{t}}+\frac{\partial \pi_{t}\left(x_{t}, p_{t}\right)}{\partial p_{t}} \frac{d p_{t}}{d x_{t}}$. As long as producers' profits are concave, conditions similar to (6) govern extraction; they exhibit the same properties as above, where $p_{t}$ is in general replaced with the inverse residual demand faced by the producer - the inverse total demand in the monopoly case. The solution is then easily adapted to this difference throughout the analysis. All results survive: the substitution effect dominates the stock effect, and policy implications such as the green paradox remain true.

The analysis also applies if the extractive firm is not the owner of the raw resource but has to buy the stock of initial reserves $X$ at a unit supply price $\mu$. At the producer's optimum, the extraction rent $\lambda$ then must equal the reserve supply price, which is given by

\footnotetext{
${ }^{15}$ If the change in demand affects a single date as in the analysis of Section 2, the drop in price unambiguously causes a drop in supply at that date. More generally if $\Delta$ contains more than a single date, the reaction of resource supply at $T \in \Delta$ depends on the magnitude of the price change occurring at that date relative to the changes occurring at other dates $T^{\prime} \in \Delta$. However, the analysis of Section 2 indicates that cumulative extraction over $\Delta$ is reduced. This is because $X$ decreases while cumulative supply at all dates $t \notin \Delta$ increases.
} 
the inverse reserve supply function $\mu=E^{\prime}(X)$. The producer's objective does not directly internalize the exploration and development cost $E(X)$, but does so via the expenditure $\mu X$. Under perfect competition, this problem is isomorphic to the problem treated in Section 2. If the resource extractor holds market power in the acquisition of initial reserves, the price parameter $\mu$ in $\mu X$ must be replaced with the relevant inverse residual supply function in the monopsony case, this is $E^{\prime}(X) X$, and $X$ is chosen in such a way that the marginal revenue $E^{\prime}(X)+E^{\prime \prime}(X) X$ equals the shadow value $\lambda$. There still exists a relation like (4) with the same properties as in Section 2; the analysis follows through and the results are unchanged as long as the extractor's problem is well-behaved, i.e. as long as the marginal expenditure on resource acquisition is increasing.

Non-renewable resources are notoriously heterogenous. One popular way to model this heterogeneity is due to Gordon (1967), has been further discussed or refined by Levhari and Liviatan (1977) and Pindyck (1978), and was used recently by Hoel (2010), Gerlagh (2011), van der Ploeg and Withagen (2012) and Grafton et al. (2012) in works related to the green paradox. In that approach, the cost of extraction increases with cumulative extraction under the rationale that least cost resources are used first. A substantial literature studies and often questions this initial intuition of Herfindahl (1967). See, e.g. Amigues et al. (1998), Gaudet and Lasserre (2011), or Salant (2012). As Slade (1988) puts it "The idea that the least-cost deposits will be extracted first is so firmly embedded in our minds that it is an often-made but rarely tested assumption underlying the construction of theoretical exhaustible-resource models." (p. 189).

Despite its unreliable theoretical and empirical foundations, Gordon's approach to resource heterogeneity is a convenient way to model aggregate supply. However, by using aggregate reserves or aggregate cumulative extraction as determinant of extraction cost, it hides the fact that aggregate supply arises from the production of individual deposits that come in a great variety of forms which differ by extraction costs, exploration and develop- 
ment costs, location, etc. Under such circumstances, the existence of an aggregate supply depending on aggregate reserves rather than the whole vector of individual reservoirs is questionable. When possible, a much better approach is to construct aggregate supply as the sum of individual firms' supplies. We do so in the Appendix, where we consider a multiplicity of different deposits indexed by $j$, developed at endogenous dates $\tau^{j}$, and contributing to the supply of a unique resource whose price is $p_{t}$. Each deposit is similar to the single deposit considered in Section 2. However deposits differ by their size $X^{j}$, their geology, location and depth or quality, as reflected in the technologies underlying both extraction $\pi_{t}^{j}\left(x_{t}^{j}, p_{t}\right)$ and exploration $E_{t}^{j}\left(X^{j}\right)$ as well as the evolution of these technologies over time. In this highly general setup, the supply from all deposits already developed at $t$ diminishes as a result of a rise in price at any date $T>t$. The intertemporal substitution effect dominates the reserve compensation effect for each active deposit, hence at the aggregate level. This reduction in supply may be sharpened by the postponement of some deposit developments. The green paradox is observed. 


\section{REFERENCES}

Amigues, J.-P., P. Favard, G. Gaudet and M. Moreaux (1998), "On the Optimal Order of Natural Resource Use when the Capacity of the Inexhaustible Substitute is Limited", Journal of Economic Theory, 80: 153-170.

Burness, H.S. (1976), "On the Taxation of Nonreplenishable Natural Resources", Journal of Environmental Economics and Management, 3: 289-311.

Cairns, R.D. (1990), "The Economics of Exploration for Non-renewable Resources", Journal of Economic Surveys, 4: 361-395.

Fischer, C., and R. Laxminarayan (2005), "Sequential Development and Exploitation of an Exhaustible Resource: Do Monopoly Rights Promote Conservation?", Journal of Environmental Economics and Management, 49: 500-515.

Fischer, C., and S.W. Salant (2012), "Alternative Climate Policies and Intertemporal Emissions Leakage: Quantifying the Green Paradox", Resources For the Future Discussion Paper $12-16$.

Gaudet, G., and P. Lasserre (1988), "On Comparing Monopoly and Competition in Exhaustible Resource Exploitation", Journal of Environmental Economics and Management, 15: $412-418$.

Gaudet, G., and P. Lasserre (2011), "The Efficient Use of Multiple Sources of a Nonrenewable Resource under Supply Cost Uncertainty", International Economic Review, 52: 245-258.

Gerlagh, R. (2011), "Too Much Oil", CESifo Economic Studies, 57: 79-102.

Gordon, R.L. (1967), "A Reinterpretation of the Pure Theory of Exhaustion", Journal of Political Economy, 75: 274-286.

Grafton, R.Q., T. Kompas and N.V. Long (2012), "Substitution between Biofuels and Fossil Fuels: Is there a Green Paradox", Journal of Environmental Economics and Management, forthcoming.

Herfindahl, O.C. (1967), "Depletion and Economic Theory", in: Extractive Resources and Taxation, Ed. M. Gaffney, University of Wisconsin Press: 63-90.

Hoel, M. (2010), "Is There a Green Paradox?", CESifo Working Paper 3168.

Levhari, D., and N. Liviatan (1977), "Notes on Hotelling's Economics of Exhaustible Resources", Canadian Journal of Economics, 10: 177-192. 
Mas-Colell, A., M.D. Whinston and J.R. Green (1995), Microeconomic Theory, Oxford University Press.

McFadden, D.L. (1978), "Duality of Production, Cost, and Profit Functions", in: Production Economics: A Dual Approach to Theory and Applications, Vol. I: The Theory of Production, Eds. M.A. Fuss and D.L. McFadden, North-Holland: 2-109.

Pindyck, R.S. (1978), "The Optimal Exploration and Production of Nonrenewable Resources", Journal of Political Economy, 86: 841-861.

van der Ploeg, F., and C. Withagen (2012), "Is There Really a Green Paradox?", Journal of Environmental Economics and Management, forthcoming.

Quyen, N.V. (1988), "The Optimal Depletion and Exploration of a Nonrenewable Resource", Econometrica, 56: 1467-1471.

Salant, S.W. (2012), "The Equilibrium Price Path of Timber in the Absence of Replanting", Resource and Energy Economics, forthcoming.

Sinn, H.-W. (2008), "Public Policies Against Global Warming: A Supply Side Approach", International Tax and Public Finance, 15: 360-394.

Slade, M.E. (1988), "Grade Selection under Uncertainty: Least Cost Last and Other Anomalies", Journal of Environmental Economics and Management, 15: 189-205.

Varian, H.R. (1992), Microeconomic Analysis, $3^{\text {rd }}$ Edition, W. W. Norton \& Company. 


\section{APPENDIX}

\section{Partial equilibrium analysis}

Suppose that prices are determined by the equilibrium of supply and demand where supply is defined as above: taking prices $p \equiv\left(p_{t}\right)_{t \geq 0}$ as given, producers solve (1) subject to (2). Equations (3)-(6) hold as before. Assume that the demand for the resource at date $t \geq 0$ only depends on the date, on the resource price at that date $p_{t}$, and on the stringency at date $t$ of demand-reducing policies, synthesized by the index $\theta_{t}$. Demand may thus be written ${ }^{16}$ $D_{t}\left(p_{t}, \theta_{t}\right)$ and assumed continuously differentiable and decreasing in both arguments. The path of the policy stringency index $\Theta \equiv\left(\theta_{t}\right)_{t \geq 0}$ is exogenously given. The inverse demand function $P_{t}\left(x_{t}, \theta_{t}\right)$ is continuously differentiable and decreasing in its two arguments.

In equilibrium, it must be that $x_{t}=x_{t}\left(P_{t}\left(x_{t}, \theta_{t}\right), \lambda\right)$, where the function $x_{t}$ is defined by (6). This implicitly defines the equilibrium quantity as a function $\phi_{t}$ which is decreasing in its two arguments:

$$
x_{t}=\phi_{t}\left(\theta_{t}, \lambda\right), \forall t \geq 0 .
$$

The rest of the analysis follows the same steps as in Section 2, with the exogenous index levels $\theta_{t}$ replacing the prices $p_{t}$. Combining (2) with (14) gives the resource rent as a function that is decreasing in all indices $\Theta$ and in the stock $X$; to simplify notation we redefine $\lambda$ to be that equilibrium rent function:

$$
\lambda=\lambda(\Theta, X) .
$$

Substituting (15) into (14) yields the equilibrium extraction flows, conditional on the stock of reserves; redefining $\widetilde{x}_{t}$ to denote that function, we have

$$
x_{t}=\widetilde{x}_{t}(\Theta, X) \equiv \phi_{t}\left(\theta_{t}, \lambda(\Theta, X)\right), \forall t \geq 0 .
$$

Equilibrium extraction quantities are increasing in $X$ and in $\theta_{t^{\prime}}, t^{\prime} \neq t$. The partial derivative of $\widetilde{x}_{t}($.$) with respect to \theta_{t}$ is negative, for the same reasons that explain the restricted supply to be increasing in the current price in Section 2.

Denote by $X^{e}$ the equilibrium amount of reserves. The unit rent in equilibrium is thus $\lambda^{e}=\lambda\left(\Theta, X^{e}\right)$. By (5), the equilibrium stock of reserves satisfies $X^{e}=X\left(\lambda^{e}\right)=$ $X\left(\lambda\left(\Theta, X^{e}\right)\right)$, which implicitly defines $X^{e}$ as a function of $\Theta$ only:

$$
X^{e}=X^{e}(\Theta) .
$$

The equilibrium stock of initial reserves is decreasing in all $\theta_{t}, t \geq 0$. Finally, the unrestricted equilibrium extraction flows $x_{t}^{e}$ are determined by

$$
x_{t}^{e}=x_{t}^{e}(\Theta) \equiv \widetilde{x}_{t}\left(\Theta, X^{e}(\Theta)\right), \forall t \geq 0 .
$$

\footnotetext{
${ }^{16}$ A less synthetic demand function could be $D_{t}\left(p_{t}\right) \equiv f_{t}\left(\alpha_{t}\right) d_{t}\left(p_{t}+\beta_{t}, p_{t}^{s}-\gamma_{t}\right)$, where $f_{t}$ is decreasing, $d_{t}$ is decreasing in its two arguments, and where $\left(\alpha_{t}\right)_{t \geq 0},\left(\beta_{t}\right)_{t \geq 0},\left(p_{t}^{s}\right)_{t \geq 0},\left(\gamma_{t}\right)_{t \geq 0}$ respectively denote the given time paths of an index of demand-reducing technical progress, of a tax on resource extraction, of the price of a substitute, and of a subsidy to this substitute. An increase in $\theta_{t}$ at any date $t$ may then reflect technical change, an increase in resource taxation, an increase in subsidies to substitutes, or any combination of such resource demand-reducing policies.
} 
By (16), the effect of a change in the stringency of policies at $T$, on the equilibrium extraction quantities $x_{t}^{e}$ at all dates $t \neq T$, can be decomposed into a substitution effect and a reserve compensation effect as in (11). Obviously the substitution effect dominates as in Section 2. Although demand-reducing policies at some dates result in lower total cumulative extraction (the stock effect), they always lead to increased equilibrium extraction flows at all dates where they have no effect on demand (the substitution effect dominates). As argued in the main text, this is also true if the resource is supplied by a monopoly or if the exploration sector is a monopsony.

\section{Resource heterogeneity: multiple deposits}

Let the various possible supply sources (deposits, developed or not) be identified by $j$, $j=1, \ldots, J$, and let resource supply at date $t$ be

$$
S_{t}=\sum_{j=1}^{J} x_{t}^{j},
$$

where $x_{t}^{j} \geq 0$ is the quantity of resource $j$ supplied at date $t$. Net spot extraction revenues are $\pi_{t}^{j}=\pi_{t}^{j}\left(x_{t}^{j}, p_{t}\right)$, with the same properties as in the single source case of Section 2 . Since $x_{t}^{j}$ may be zero, there is no loss of generality in assuming that the same countable set of dates applies for all sources. Each source is constrained by its own finite reserve stock. As the marginal reserve unit of any deposit will only be developed if it is to be exploited, that constraint binds: ${ }^{17}$

$$
\sum_{t \geq 0} x_{t}^{j}=X^{j}, j=1, \ldots, J
$$

Each source is characterized by its own exploration and development cost $E_{t}^{j}\left(X^{j}\right)$ whose qualitative properties are the same as in the case of a single resource, with the following minor difference. The property $E^{j \prime}(0)=0$ is replaced with $E_{t}^{j \prime}(0) \geq 0$, so that a resource whose marginal exploration and development cost is too high for profitability need not be developed. However the same deposit that is not economic at date zero may be developed when prices become higher and/or when the technologies encompassed in the functions $\pi_{t}^{j}$ and $E_{t}^{j}$ justify it. ${ }^{18}$ We assume that technological progress on exploration and development is such that, for any date $t^{\prime}>t$ and initial reserves $X^{j^{\prime}}>X^{j}$,

$$
E_{t}^{j}\left(X^{j}\right) \geq E_{t^{\prime}}^{j}\left(X^{j}\right) \text { and } E_{t}^{j}\left(X^{j^{\prime}}\right)-E_{t^{\prime}}^{j}\left(X^{j^{\prime}}\right) \geq E_{t}^{j}\left(X^{j}\right)-E_{t^{\prime}}^{j}\left(X^{j}\right), \forall j .
$$

As before, it is supposed that exploration and development are instantaneous and undertaken only once for each deposit; extraction may take place only after deposit development.

\footnotetext{
${ }^{17}$ If deposit $j$ is never developed, $\sum_{t \geq 0} x_{t}^{j}=0=X^{j}$.

${ }^{18}$ It is well-known that, for some price and technology combinations, development occurs only at $\tau=0$ if at all. Such is the case, for example, if prices are constant while extraction and development technologies are stationary.
} 
All potential producers face the same given known price stream. For source $j$, the producer solves

$$
\max _{\left(x_{t}^{j}\right)_{t \geq 0}, X^{j}, \tau^{j}} \sum_{t \geq 0} \pi_{t}^{j}\left(x_{t}^{j}, p_{t}\right)(1+r)^{-t}-(1+r)^{-\tau^{j}} E_{\tau^{j}}^{j}\left(X^{j}\right)
$$

subject to (20) and to

$$
x_{t}^{j}=0, t<\tau^{j},
$$

where $\tau^{j} \geq 0$ is the development date for deposit $j$. There is one specific resource rent $\lambda^{j}$ associated with each deposit. Suppose that $\tau^{j}>0$. No production occurs before that date, so that $x_{t}^{j}=0, t<\tau^{j}$. We further assume that the combination of resource price changes and technological change affecting $\pi_{t}^{j}$ is such that, once initiated, production is not interrupted until exhaustion. ${ }^{19}$ We also assume that the problem is well behaved in the sense that the optima being characterized are global rather than local, at least in the neighborhood of the price vector under consideration. This rules out jumps from one local maximum to another local maximum as a result of a change in the price vector. Clearly, the problems to be solved for each source are independent of each other. Thus the sole difference with the one-resource case analyzed earlier is the fact that all resources need not be developed at date zero if at all. Roughly, given a price path, resources whose extraction cost is higher and/or whose cost of exploration and development is higher will be developed later. We are interested in aggregate resource supply at dates $t \geq 0$; in particular we want to determine how supply $S_{t}$ reacts to a change in price at $T \geq t$. Since each component $x_{t}^{j}$ of $S_{t}$ is determined independently of the others, consider deposit $j$ in particular.

Suppose at this stage that the development date $\tau^{j}$ is given. Then the derivations and properties established in Section 2 for Problem (1) can be readily adapted to Problem (22). If $\tau^{j}=0$ the solution is identical to that of Section 2; if $\tau^{j}>0, x_{t}^{j}=0$ when $t<\tau^{j}$ and, for $t \geq \tau^{j}$, the first-order conditions for the choice of the optimum extraction path and initial reserves are, instead of (3) and (4),

$$
\frac{\partial \pi_{t}^{j}\left(x_{t}^{j}, p_{t}\right)}{\partial x_{t}^{j}}(1+r)^{-t}=\lambda^{j}, \forall t \geq \tau^{j},
$$

and

$$
E_{\tau^{j}}^{j \prime}\left(X^{j}\right)=(1+r)^{\tau^{j}} \lambda^{j},
$$

where all values, including the unit Hotelling scarcity rent $\lambda^{j}$, are evaluated at date zero, although development occurs at $\tau^{j}$ rather than at zero.

All properties of the supply functions established in Section 2 apply for each deposit, provided it is active at $t$. Still holding $\tau^{j}$ constant, consider the effect of an increase in price at date $T$ on date- $t$ industry supply, where $T \geq t$. All deposits developed at or before $t$

\footnotetext{
${ }^{19}$ This assumption greatly facilitates the analysis while it eliminates situations of only minor economic interest. It is satisfied if prices do not diminish too fast and technological change is such that extraction costs do not increase too fast over any part of the exploitation period.
} 
contribute to $S_{t}$. Consequently the effect is the sum of the changes in the supply from all deposits such that $\tau^{j} \leq t \leq T$ : if $t<T$, an increase in $p_{T}$ reduces extraction from all active deposits at $t$ reducing total supply at $t$. If $t=T$, a rise in $p_{T}$ increases the contribution from all deposits, thus increasing total supply at $t$.

Now allow optimal development dates to adjust to the price change. As in Section 2, a "*" next to a variable or function refers to the optimal unrestricted level of the variable or to the unrestricted function. The optimal development date $\tau^{j *}(p)$ of deposit $j$ may be a corner solution $\tau^{j *}(p)=0$ or, if it is an interior solution, it is an integer value $\tau^{j *}(p)>0$ within the set of possible dates. For an interior solution, the Lagrangian $\mathcal{L}\left(x^{j *}, X^{j *}, \tau, \lambda^{j *}\right)$ for Problem (22) must be bigger at $\tau^{j *}(p)$ than at $\tau^{j *}(p)-1$ and at $\tau^{j *}(p)+1$. The implied inequalities $\mathcal{L}\left(x^{j *}, X^{j *}, \tau, \lambda^{j *}\right)-\mathcal{L}\left(x^{j *}, X^{j *}, \tau-1, \lambda^{j *}\right)>0$ and $\mathcal{L}\left(x^{j *}, X^{j *}, \tau, \lambda^{j *}\right)-$ $\mathcal{L}\left(x^{j *}, X^{j *}, \tau+1, \lambda^{j *}\right)>0$ when $\tau=\tau^{j *}$ can be written as

$$
\begin{aligned}
r E_{\tau-1}^{j}\left(X^{j *}\right)+E_{\tau-1}^{j}\left(X^{j *}\right)-E_{\tau}^{j}\left(X^{j *}\right) & >\pi_{\tau-1}^{j}\left(x_{\tau-1}^{j *}, p_{t}\right)(1+r)-(1+r)^{\tau} \lambda^{j *} x_{\tau-1}^{j *}, \\
\frac{r}{1+r} E_{\tau+1}^{j}\left(X^{j *}\right)+E_{\tau}^{j}\left(X^{j *}\right)-E_{\tau+1}^{j}\left(X^{j *}\right) & <\pi_{\tau}^{j}\left(x_{\tau}^{j *}, p_{t}\right)-(1+r)^{\tau} \lambda^{j *} x_{\tau}^{j *}
\end{aligned}
$$

The assumption that the optimum is global further implies that the Lagrangian is increasing in $\tau$ before $\tau^{j *}-1$ and decreasing after $\tau^{j *}+1$.

Consider a change in the price schedule from $p$ to $p^{\prime}$ where $p^{\prime}$ departs from $p$ because of an increase in $p_{T}$ at some date $T>\tau=\tau^{j *}(p)$. We know that $\lambda^{j *}\left(p^{\prime}\right)>\lambda^{j *}(p)$. Then since $p_{t}$ is unchanged at any $t<T$, the concavity of $\pi_{t}^{j}$ in $x_{t}^{j}$ implies that $x_{t}^{j / *}<x_{t}^{j *}$, $\forall t \in\left\{\tau^{j *}\left(p^{\prime}\right), \ldots, T-1\right\}$ by $(23)$. However, the fact that production from any existing deposit $j$ is diminished at dates $t \in\left\{\tau^{j *}\left(p^{\prime}\right), \ldots, T-1\right\}$ following the increase in $p_{T}$ is not sufficient to conclude to a drop in production at these dates: it is also necessary that no deposit comes into stream at the new price if it was not in production at the old price vector at any of these dates. That is to say, if a deposit is developed at $\tau^{j *}\left(p^{\prime}\right)=t, t \in\{0, \ldots, T-1\}$, it must be the case that it was under operation at, or before, $t$ at the old price vector: we must show that $\forall j, \tau^{j *}\left(p^{\prime}\right) \geq \tau^{j *}(p)$.

Consider (25) and (26) at $\tau=\tau^{j *}(p)<T$ for any $j$ when $\lambda^{j *}(p)$ increases to $\lambda^{j *}\left(p^{\prime}\right)$. The right-hand sides of both expressions are diminished. Since $X^{j *}$ increases by (24) as a result of the increase in $\lambda^{j *}$, the monotonicity of $E_{t}^{j}$ and Assumption (21) imply that the left-hand sides of both expressions increase. This means that (25) remains satisfied if $\tau^{j}$ is not adjusted, while (26) may become violated; in such case, only an increase in $\tau^{j}$ can reestablish the optimality conditions. Consequently, $\tau^{j *}\left(p^{\prime}\right) \geq \tau^{j *}(p)$, completing the proof that, if $t<T$, an increase in $p_{T}$ not only reduces extraction from active deposits but may also cause the development of some deposits at or before $t$ to be postponed.

Similar arguments show that, if $t=T$, an increase in $p_{T}$ increases supply at $t$. 